\title{
THE LEFT VENTRICULAR OUTFLOW TRACT IN ATRIOVENTRICULAR SEPTAL DEFECT REVISITED: SURGICAL CONSIDERATIONS REGARDING PRESERVATION OF AORTIC VALVE INTEGRITY IN THE PERSPECTIVE OF ANATOMIC OBSERVATIONS
}

Yuichi Shiokawa, MD

Anton E. Becker, MD, PhD
Objective: The anatomy of the left ventricular outflow tract in hearts with atrioventricular septal defect has been widely investigated, but controversies remain regarding detailed aspects of left ventricular outflow tract anatomy in the perspective of operative techniques to either prevent or relieve outflow tract obstruction. Methods: We investigated 29 postmortem hearts with an atrioventricular septal defect. Measurements were taken of the circumferences and of the widths of the components that make up the outflow tract, that is, the interventricular septum, the superior bridging leaflet, the left ventricular free wall, and the length of the tendinous cords. Results: The circumference of the left ventricular outflow tract immediately underneath the aortic valve was not different from that at the middle part of the outflow tract. Hearts with the partial type defect, characterized by separate atrioventricular orifices, had a smaller outflow tract than those with the complete variety. Although the anatomic constituents that contribute to left ventricular outflow tract obstruction are complex, this study showed that a reduced width of the interventricular septum was most intimately related to narrowing immediately underneath the aortic valve. Obstruction at the middle part of the left ventricular outflow tract was largely caused by reduced width of the interventricular septum together with short tendinous cords. Conclusions: On the basis of these observations, we recommend detailed investigation of the anatomy of the left ventricular outflow tract immediately underneath the aortic valve, before surgical attempts to relieve outflow tract obstruction, because in some procedures the integrity of the aortic valve will be at stake. (J Thorac Cardiovasc Surg 1997;114:586-93) eft ventricular outflow tract (LVOT) obstruction -in hearts with an atrioventricular (AV) septal defect $^{1}$ remains a major surgical challenge. The intrinsic anatomy of these hearts is such that the potential for LVOT obstruction is always present,

From the Department of Cardiovascular Pathology, Academic Medical Center, University of Amsterdam, Amsterdam, The Netherlands.

During the course of this study Dr. Shiokawa was a research fellow from the Fukuoka Children's Hospital and Medical Center for Infectious Diseases, Fukuoka, Japan.

Received for publication Dec. 30, 1996; revisions requested April 17, 1997; revisions received May 12, 1997; accepted for publication May 14, 1997.

Address for reprints: Anton E. Becker, MD, Department of Cardiovascular Pathology, Academic Medical Center, University of Amsterdam, P.O. Box 22700, 1100 DE Amsterdam, The Netherlands.

Copyright $@ 1997$ by Mosby-Year Book, Inc.

$0022-5223 / 97 \$ 5.00+0 \quad \mathbf{1 2 / 1 / 8 3 2 2 7}$ albeit more pronounced in hearts with two separate AV orifices (partial type) than in those with a common orifice (complete type). ${ }^{2,3}$ The presence of LVOT obstruction has an important impact on postoperative mortality ${ }^{4}$ and morbidity. ${ }^{3,5}$ Of equal importance, clinically important stenosis is a consequence of surgical repair of AV septal defect in $3 \%$ to $7 \%$ of patients. ${ }^{2,5-7}$

Several surgical techniques have been proposed to overcome the problem of LVOT obstruction, such as fibromyectomy, patch enlargement of the outlet septum (the so-called modified Konno operation), and patch insertion after detachment of a tightly adherent left superior leaflet. ${ }^{2,5,8,9}$ Despite some reports documenting good postoperative results, ${ }^{2}$ our own experience and that of others ${ }^{5}$ is less favorable. An alternative approach, in patients with the complete variety, having a common $\mathrm{AV}$ orifice, is conversion of a Rastelli type A lesion into a Rastelli type C anatomy. ${ }^{2,5,10}$ The success rate of this type of repair, 


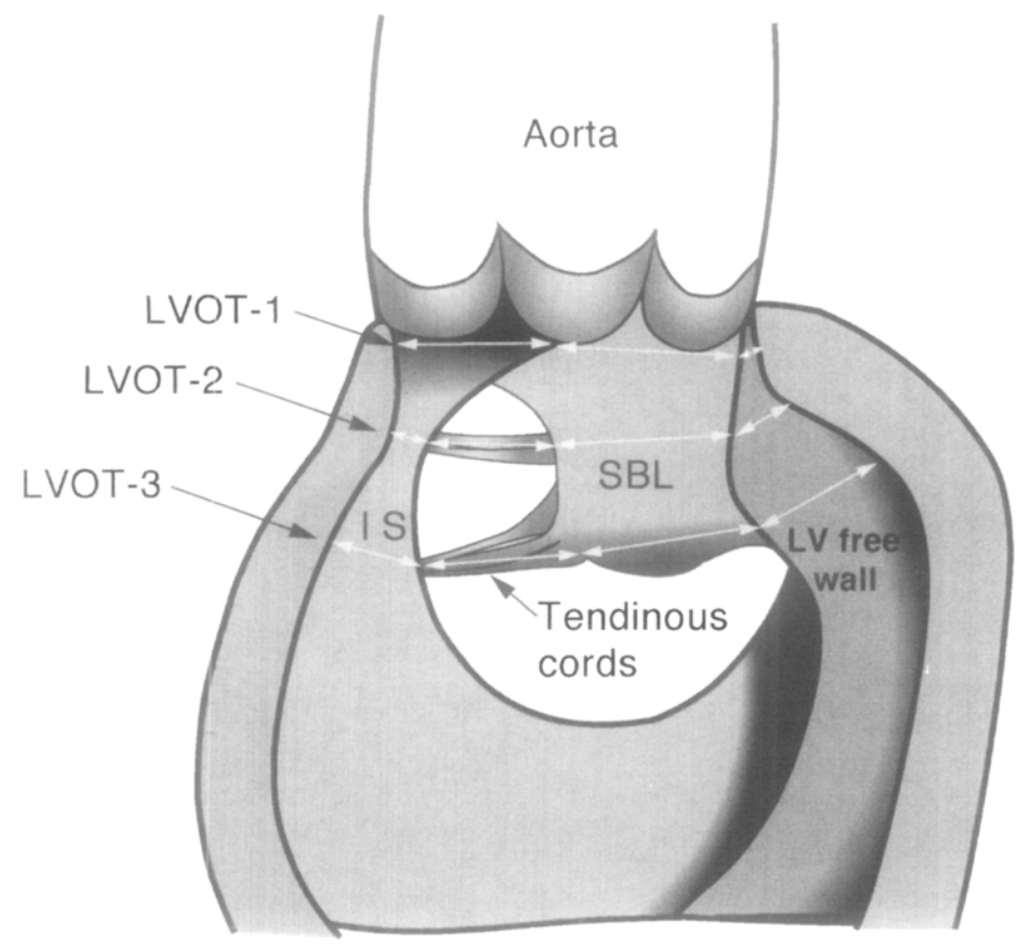

Fig. 1. Diagram of the LVOT in hearts with AV septal defect. Shown are the three levels (LVOT-1, LVOT-2, and LVOT-3) at which measurements were taken, together with those of the width of the interventricular septum $(I S)$, the width of the anterior left ventricular $(L V)$ free wall, that of the superior bridging leaflet (SBL), and the length of the tendinous cords.

however, appears to be rather low. Indeed, to the best of our knowledge, success with this approach has been reported in only one patient thus far. ${ }^{10}$ The authors of this report commented that the size of the aortic root itself was a major limitation to successful outcome.

Because we have experienced the same problems, we designed the present study in which we have examined the LVOT in hearts with AV septal defect with special reference to the contribution of the various components that together form the LVOT and, in particular, the detailed anatomy immediately underneath the aortic root.

\section{Materials and methods}

We examined 29 hearts with an AV septal defect stored in our cardiovascular registry. All hearts had a usual atrial arrangement, concordant AV connection, and balanced ventricles; hearts associated with overriding of the aorta were excluded. The hearts were divided into two groups: the first group consisted of hearts with the partial type defect containing two separate AV orifices (11 cases), and the second group comprised hearts with the complete type having a common AV orifice (18 cases). None of the hearts with a partial type defect contained a ventricular septal defect. The complete type contained 14 hearts with the superior bridging leaflet attached by tendinous cords to the septum (so-called Rastelli type A) and four hearts with a free-floating superior bridging leaflet (so-called Rastelli type C).

Fig. 1 shows the measurements taken at three different planes: LVOT-1 was immediately underneath the aortic valve, LVOT-2 was at the level with the smallest width of the outflow part of the interventricular septum, and LVOT-3 represented the site of junction with the inlet septum. The following measurements were made: the anteroposterior width of the infundibular septum, the width of the left ventricular free wall and that of the superior bridging leaflet, and the length of the tendinous cords. We also measured the circumference of the ascending aorta at the plane of the sinotubular junction. All measurements were expressed as a ratio of the aortic circumference. The LVOT was considered narrow once the LVOT/ascending aorta ratio was less than 0.7 .

Statistical analysis. All values are expressed as mean \pm one standard deviation. Ratios obtained by measurements in hearts with the complete type and those with the partial type were compared with the use of Mann-Whitney's $U$ test. Comparisons among more than three groups were done by means of Scheffé's F test. For all tests, $p<0.05$ was considered significant.

\section{Results}

Seven hearts $(24 \%)$ of 29 had a ratio of less than 0.7 ; six were of the partial variety with separate $\mathrm{AV}$ 

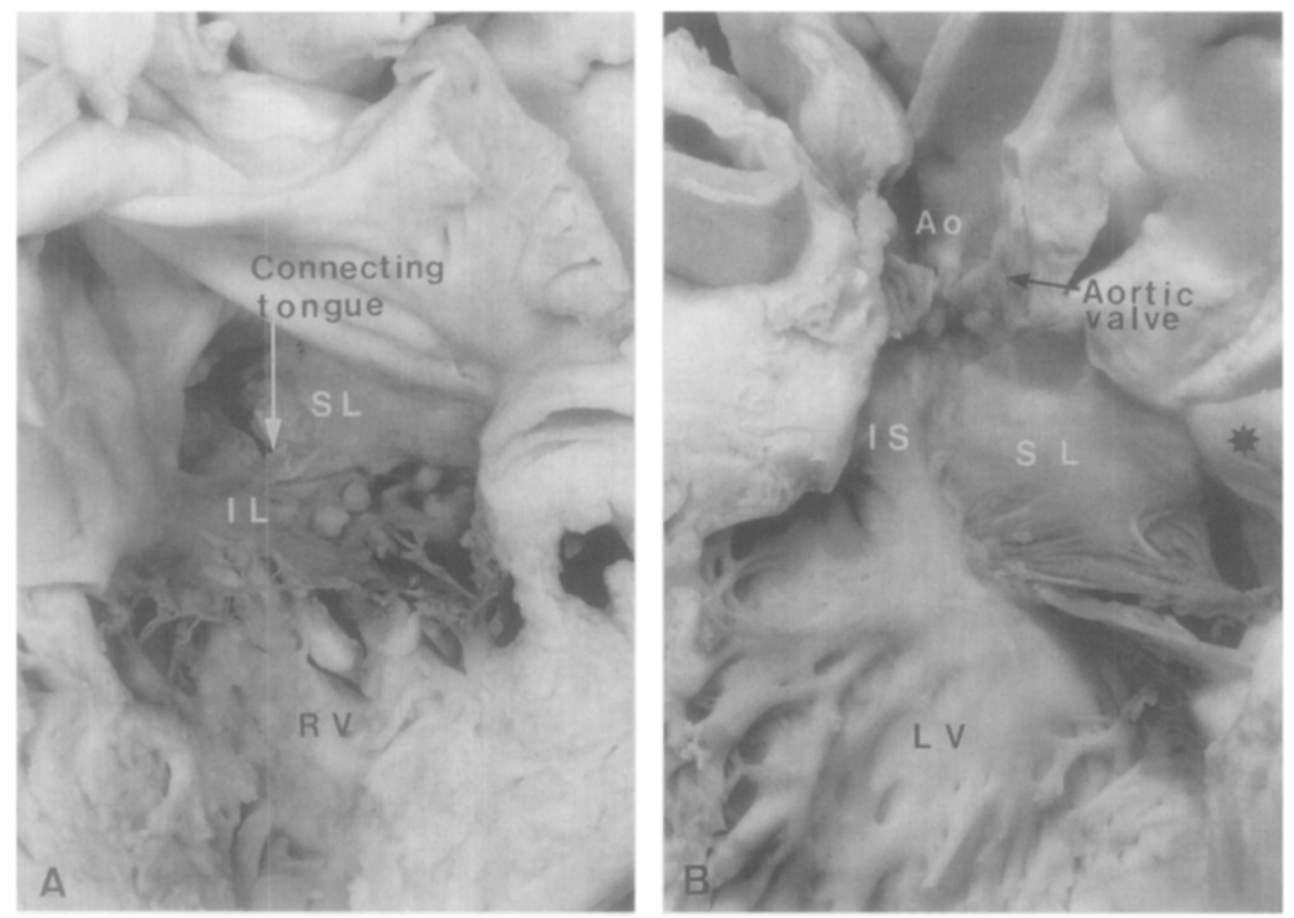

Fig. 2. AV septal defect of the partial type with separate AV orifices. A, Right ventricular view showing a connecting tongue between the superior $(S L)$ and inferior leaflet $(I L)$. B, Left ventricular view showing direct insertion of the superior leaflet $(S L)$ into the interventricular septum (IS). The "borderline" is only slightly concave. Asterisk shows left ventricular free wall. $A o$, Aorta; $L V$, left ventricle; $R V$, right ventricle,

orifices (Fig. 2) and one was of the complete type with the superior bridging leaflet attached to the septum by tendinous cords (Fig. 3). The LVOT/ ascending aorta ratio at each of the three levels (LVOT-1, LVOT-2, and LVOT-3) is shown in Fig. 4. It appears that the mean ratio at level LVOT-1 was not different from that at level LVOT-2. We found only one heart, a case with a common AV orifice (Rastelli type A), with a relatively large LVOT-1 (ratio $=0.979)$ despite a narrow LVOT-2 (ratio $<0.7$ ). In all instances the circumference at level LVOT-3 was similar to that of the ascending aorta.

Moreover, the mean ratio of the LVOT to the ascending aorta showed no statistically significant difference between the partial and the complete types of AV septal defect ( $p=0.062$ for LVOT-1, $p=0.053$ for LVOT-2). On the other hand, the same comparison at level LVOT-3 showed a significantly smaller LVOT in hearts with separate AV orifices $(p=0.039)$. This observation, nevertheless, may have no clinical relevance because in both conditions the mean ratio was greater than 1.0 (Fig. 4).
Interventricular septum. Overall the anteroposterior width of the interventricular septum in hearts with an AV septal defect is short because of the "scooped" septum. This fact is generally considered to be responsible for the intrinsic narrowing of the LVOT. However, the line of the interventricular septum facing the superior bridging leaflet often showed a concave contour (Fig. 5). The ratio of the width of the interventricular septum to the circumference of the ascending aorta is shown in Fig. 6, $A$. These data unequivocally indicate that the width of the interventricular septum depends on the level within the LVOT. It is apparent that the septum is wider at levels LVOT-1 and LVOT-3 than at level LVOT-2. Moreover, the septum immediately underneath the aortic valve was significantly wider in hearts with the complete variety than in hearts with the partial type $(p=0.041)$.

Tendinous cords. In contrast to the LVOT immediately underneath the aortic valve, the levels LVOT-2 and LVOT-3 possess tendinous cords as an integral component. In hearts with the partial type, the superior leaflet inserted directly into the ventricular septum; in case cords were present, they were 

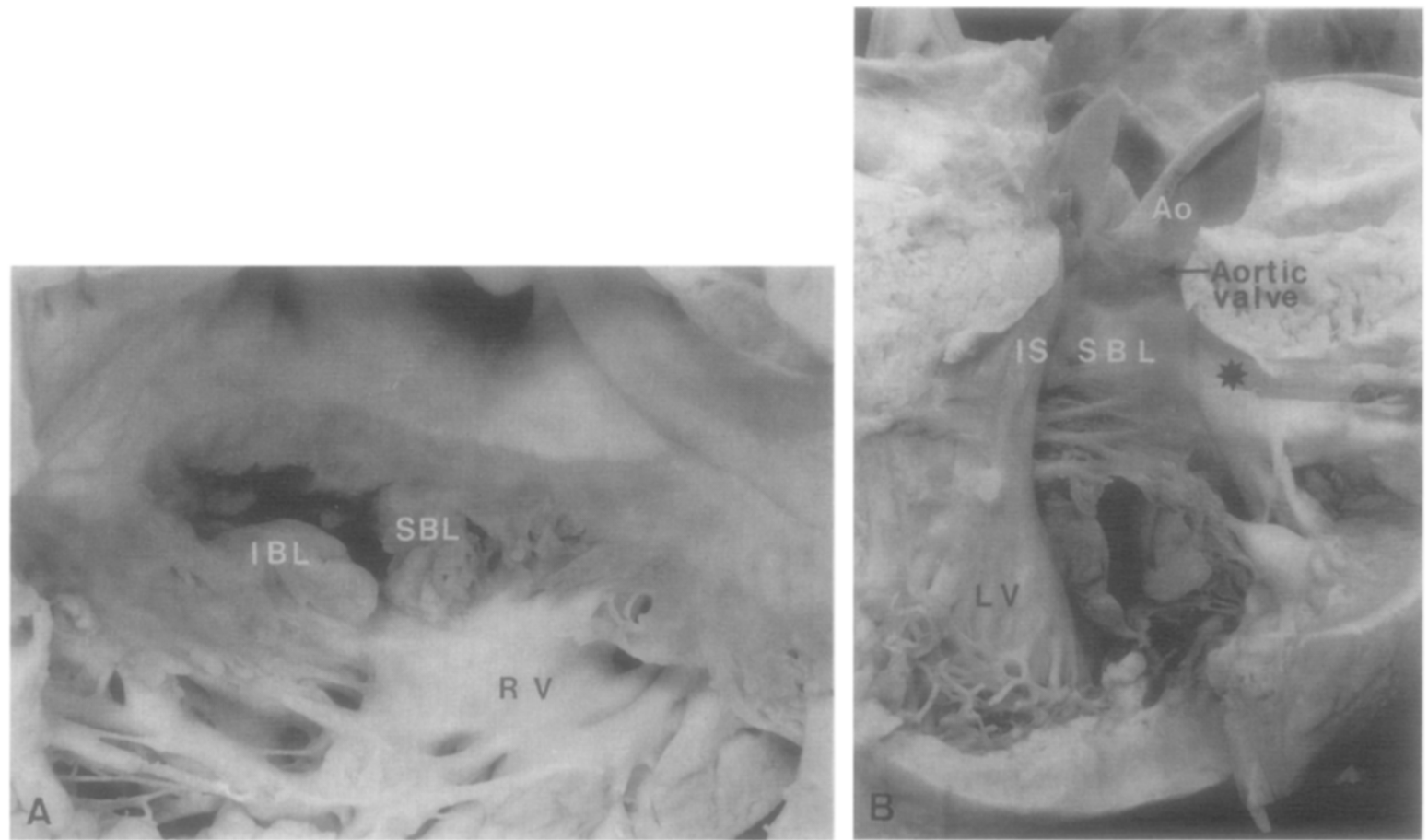

Fig. 3. AV septal defect of the complete type with a common AV orifice. A, Right ventricular view showing no connecting tongue between the superior bridging leaflet $(S B L)$ and inferior bridging leaflet (IBL). B, Left ventricular view showing attachment between the superior bridging leaflet and ventricular septum by tendinous cords. Subaortic extension of the interventricular septum (IS) is deficient, which creates an almost straight line. Asterisk shows left ventricular free wall. Ao, Aorta; $L V$, left ventricle; $R V$, right ventricle.

short and fused (see Fig. 2). Fig. 6, $B$ shows the mean ratio of the length of the cords compared with the circumference of the ascending aorta. The ratio in partial type hearts was significantly smaller than that in hearts with the complete variety, both at level LVOT-2 and at LVOT-3.

Left ventricular free wall. The ventricular free wall at levels LVOT- 1 and LVOT-2 is considerably shorter than at level LVOT-3 (Fig. 6, C). Indeed, this component was often almost unmeasurable at level LVOT-1, immediately underneath the aortic valve (see Figs. 2 and 3). It thus appears that the reduced width of the left ventricular free wall plays a role in rendering the LVOT narrow at levels LVOT-1 and LVOT-2.

Superior bridging leaflet. The superior bridging leaflet is always a substantial component of the LVOT (Fig. 7). Fig. 6, $D$ shows the ratio of this component to the circumference of the ascending aorta. The ratio was smallest at level LVOT-2 in most cases. In cases in which the tendinous cords were absent, the ratio of this component was small-

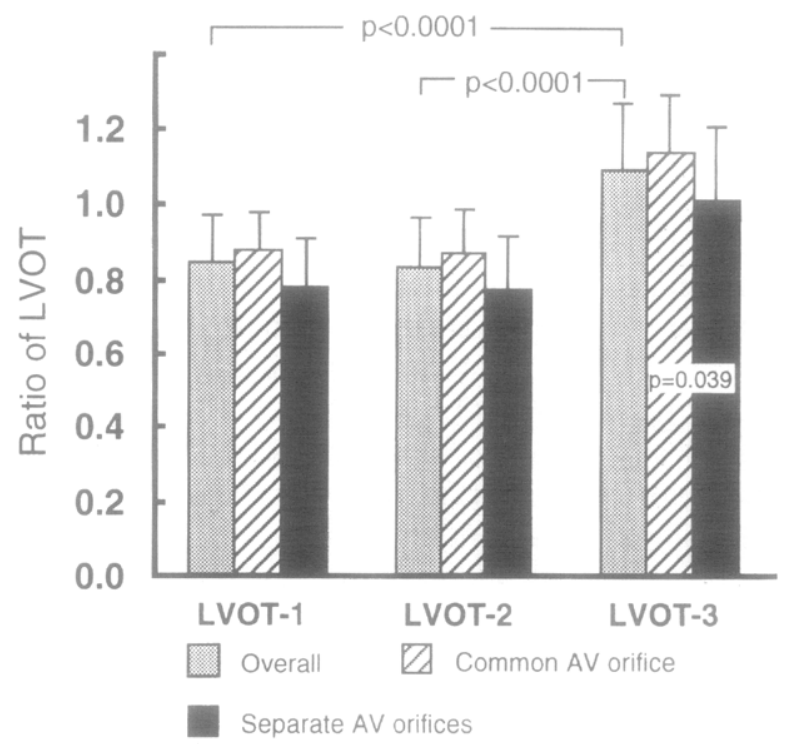

Fig. 4. LVOT/ascending aorta ratio in 29 heart specimens, showing the overall results and the subcategorization into those with a common (complete type) and those with two separate AV orifices (partial type). 

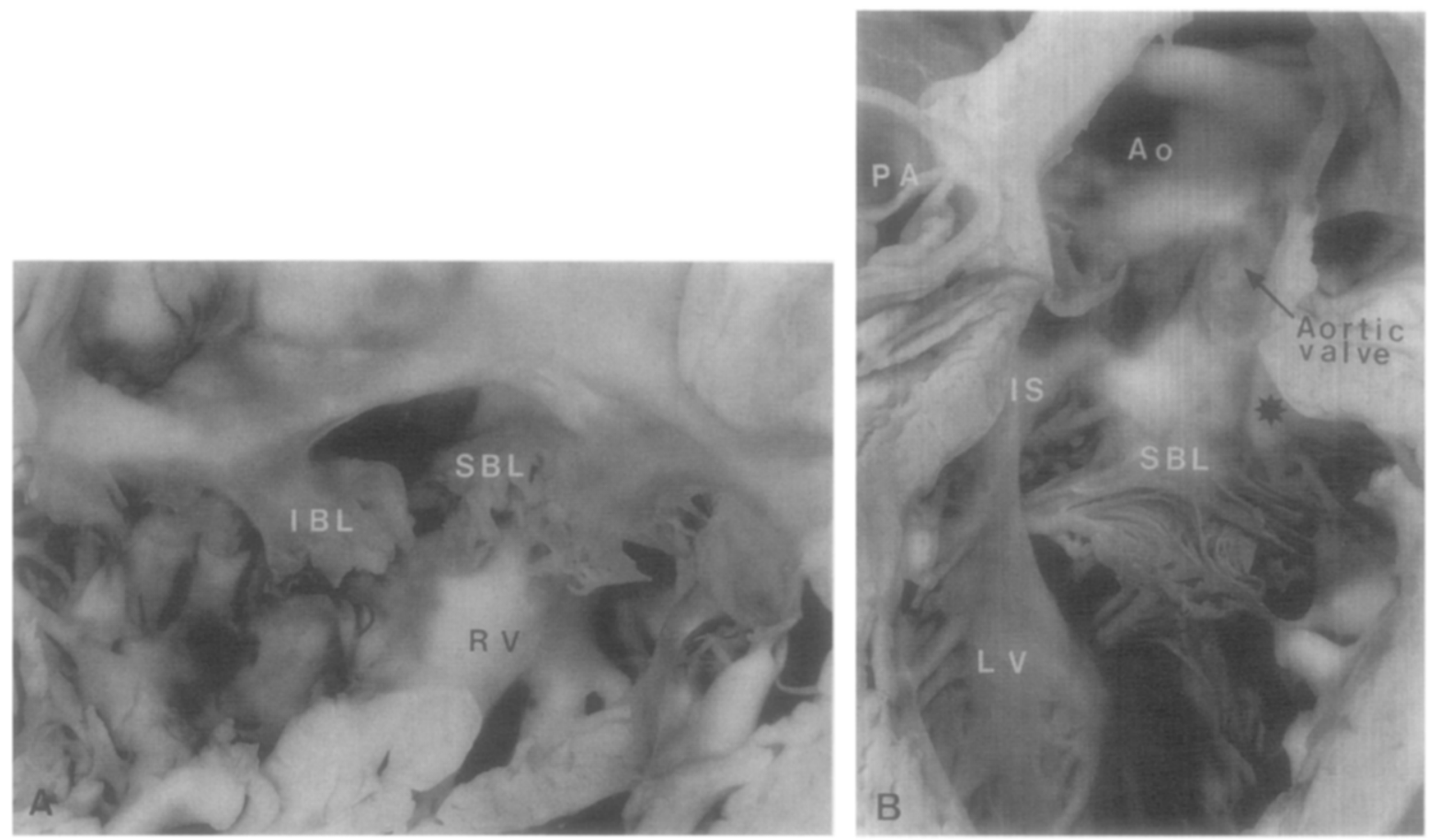

Fig. 5. AV septal defect of the complete type with a common AV orifice. A, Right ventricular view showing the Rastelli type A arrangement. Left ventricular view (B) shows a reasonably wide LVOT. The concave outline of the interventricular septum $(I S)$ is apparent. Asterisk shows left ventricular free wall. $A O$, Aorta; $I B L$, inferior bridging leaflet; $L V$, left ventricle; $R V$, right ventricle; $P A$, pulmonary artery; $S B L$, superior bridging leaflet.

est immediately underneath the aortic valve (see Fig. 2).

Proportion of each component to the total circumference of the LVOT. Fig. 7 shows the proportion of the ratio of each component compared with the total circumference of the LVOT related to each of the three levels. The component that possessed the greatest percentage was always the valve leaflet, whereas tendinous cords contributed the lowest percentage. At the level immediately underneath the aortic valve (LVOT-1), the LVOT was made up almost solely by the superior bridging leaflet and interventricular septum; the chordal contribution was completely absent and that of the left ventricular free wall was minimal. On the other hand, the percentage contribution of the other components was almost in balance, be it at level LVOT- 2 or LVOT-3.

\section{Discussion}

Although the basic architecture of the LVOT in hearts with $A V$ septal defect is the same between hearts, it does appear that important variations occur with respect to the components that potentially contribute to intrinsic narrowing of the LVOT. Several studies have addressed these anatomic features. Draulans-Noe and Wenink ${ }^{11}$ attributed the cause of LVOT obstruction mainly to a decrease in the width of the interventricular septum and to protrusion of the anterolateral muscle bundle into the LVOT. On the other hand, Ebels and associates $^{12}$ emphasized that the mode of connection between the superior bridging leaflet and the septal crest was the key to potential LVOT obstruction. We certainly agree that each of these anatomic aspects plays a role in its own right, but it appears thus far that no studies have been designed specifically to compare the immediate subaortic LVOT dimensions with those at lower levels. To the best of our knowledge, our study is the first to draw attention to the subtle anatomic differences at various levels within the LVOT, which nevertheless may have a major impact on surgical results.

In this study we have taken the stance that LVOT narrowing was present if the LVOT/ascending aorta. ratio was less than 0.7 . We have opted for this 
The Journal of Thoracic and

Cardiovascular Surgery

Shiokawa and Becker

591

volume 114, Number 4

(A)

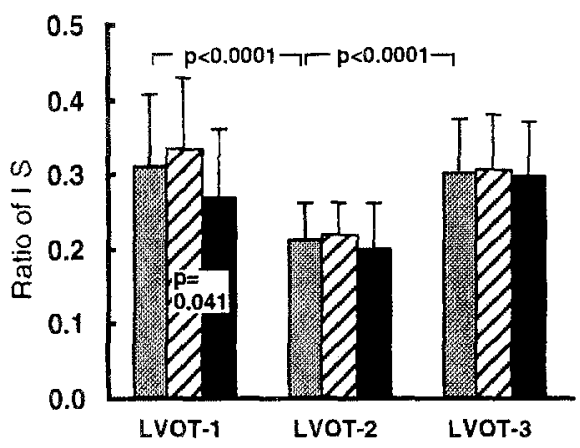

(C)

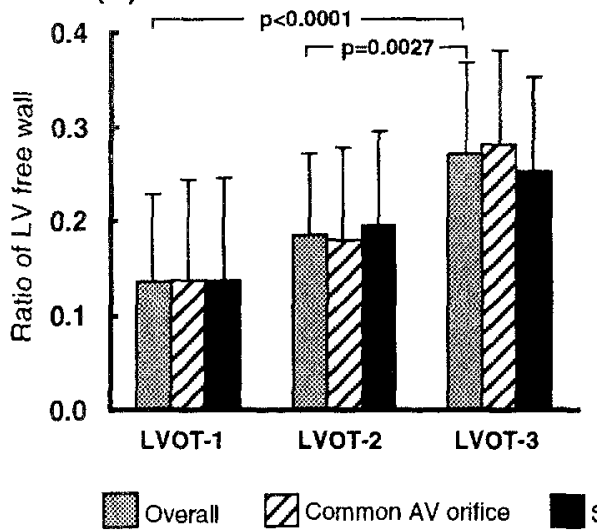

(B)

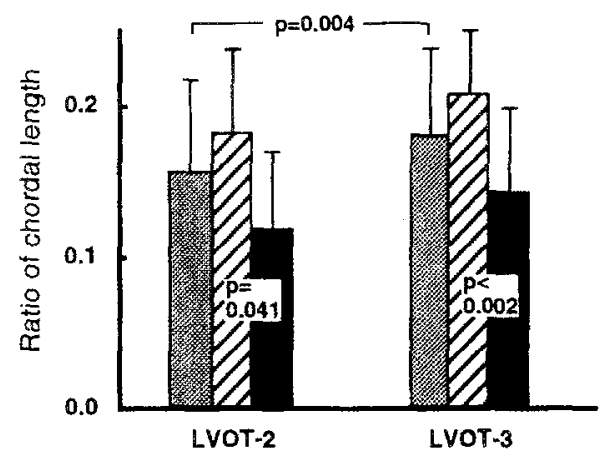

(D)

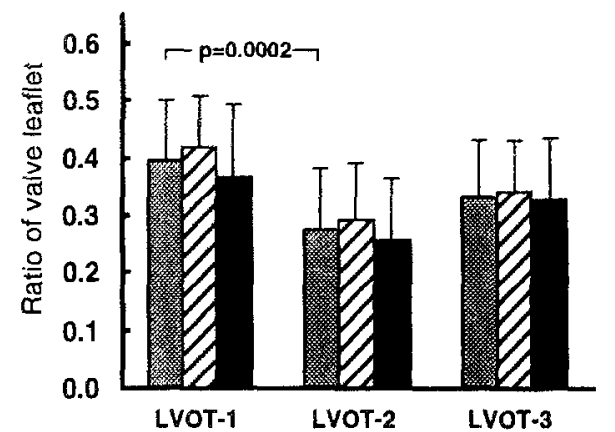

Fig. 6. Graphs showing the ratios of the measurements of the interventricular septum (IS), the tendinous cords, the left ventricular $(L V)$ free wall, and the valve leaflet related to the circumference of the ascending aorta. The overall ratios are shown as well as those of hearts with a common (complete type) and separate AV orifice (partial type). $A V$, Atrioventricular.

criterion on the basis of the occasional clinical report that provides data concerning what is considered clinically important LVOT obstruction, albeit these studies were based on patients with a ventricular septal defect and obstructive aortic arch disease. However, we see no reason why such a ratio should not be applicable to hearts with an AV septal defect also. Iwahara and associates ${ }^{13}$ reported that the operative mortality, in case of primary repair, increased once the LVOT/ascending aorta ratio measured by echocardiography was less than 0.7 . Bove and associates, ${ }^{14}$ moreover, reported significant LVOT stenosis in two of their patients, each with a descending aorta ratio of 0.65 . We have used a ratio of less than 0.7 , which we consider justifiable although some degree of shrinkage may have taken place during the process of fixation of these specimens.

It appears that at different levels in the LVOT different structures contribute to the potential nar-

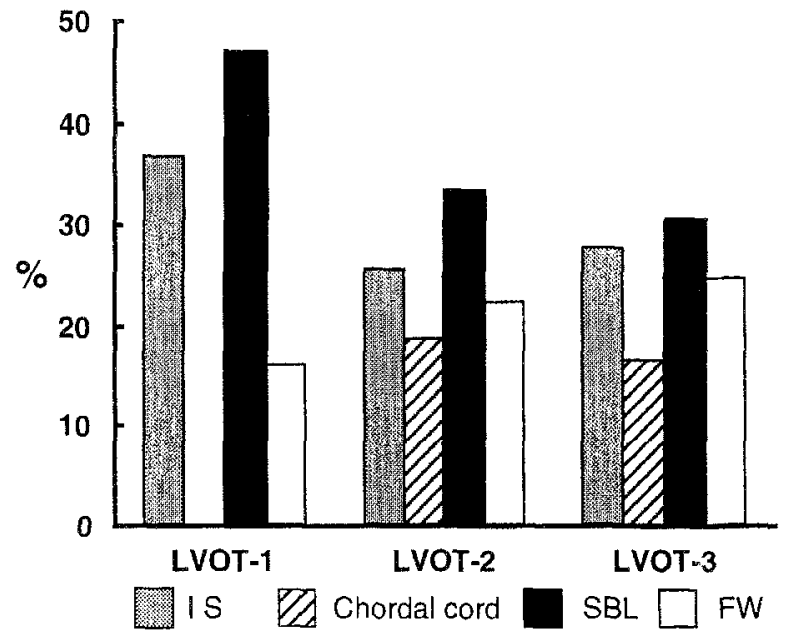

Fig. 7. Graph showing the proportion of the ratio of the interventricular septum (IS), the tendinous cords, the superior (bridging) leaftet ( $S B L$ ), and the anterior free wall $(F W)$ compared with the total circumference at the three levels (LVOT-1, LVOT-2, and LVOT-3). 
rowness. In the immediate subaortic region there is fibrous continuity between the left $A V$ valve and aortic valve without chordal insertions. Hence the circumference of the LVOT at this level is largely determined by that of the aortic root itself and by the width of the interventricular septum and the superior bridging leaflet. If the interventricular septum is reduced in size, as was often the case in our anatomic series, it is likely that the LVOT will be obstructed. On the other hand, at the middle part of the LVOT, at the site where the width of the interventricular septum was shortest, the length of the tendinous cords appears to be the major limiting factor to determine the eventual circumference of the LVOT. At the lowest level, in the inferior part of the LVOT at the site where the outlet part of the septum fuses with the inlet septum, the circumference in all instances was sufficient to warrant an unobstructed inlet into the LVOT.

Most previous reports have stressed that hearts with a partial type defect, characterized by two separate AV orifices, are more prone to have LVOT obstruction than hearts with the complete type, having a common AV orifice. ${ }^{3,4,7,9,12}$ In fact, Ebels and associates ${ }^{15}$ indicated that the reason for this situation is the tight connection between the septal crest and the "bridging" valve leaflet in hearts with separate AV valves, whereas in those with a common orifice the truly bridging leaflet is more loosely attached to the crest by tendinous cords. Our results fully endorse their conclusions. The length of the tendinous cords in hearts with separate AV orifices was much shorter than in those with a common $\mathrm{AV}$ orifice. Occasionally, no cords were present whatsoever and the leaflet was inserted directly into the crest of the septum.

However, the fact that a similar situation, characterized by short tendinous cords and a bridging leaflet tightly tethered to the crest of the ventricular septum, may occur also in hearts with an AV septal defect of the complete type appears to be underestimated. Van Arsdell and coworkers ${ }^{5}$ documented a high rate of recurrence after reoperation for subaortic stenosis in patients with AV septal defect. They suggested that converting a Rastelli type A to a type $\mathrm{C}$ lesion with dissection of the connecting tissue between the superior bridging leaflet and the ventricular septum, followed by patch insertion, may have a beneficial effect. However, DeLeon and colleagues, ${ }^{2}$ who practiced this method, warned that this procedure had serious limitations beyond a serious risk of mitral valve regurgitation. Thus far only Starr and Hovaguimian ${ }^{10}$ have reported a successful repair using this technique. Furthermore, in a commentary on Van Arsdell's report, ${ }^{5}$ Starr mentioned three cases in which this method of repair was used, two of which were successful. He also mentioned that in the unsuccessfully repaired case the aortic anulus was underdeveloped and this patient would have needed some kind of valve replacement because of a residual pressure gradient.

This brings us to the crux of our study. Our observations clearly show that the LVOT immediately underneath the aortic valve was as narrow as the most narrow part of the LVOT at a more proximal level, usually considered the site to be relieved. Hence simple detachment of tendinous cords considered to cause major narrowing in the middle part of the LVOT has little effect on the more distal part of the LVOT and, simply because of these anatomic configurations, may result in a residual postoperative pressure gradient. It would be worthwhile, therefore, if preoperative evaluations in these patients, such as echocardiographic or magnetic resonance imaging studies, could focus on these particular anatomic aspects. Although incision of the aortic root with valve replacement, the socalled Konno procedure, is not considered to be an accepted option for surgeons, particularly for the very young patient, some hearts will have an anatomic configuration of the LVOT in which adequate release of obstruction can be achieved only by sacrificing the aortic valve.

\section{REFERENCES}

1. Becker AE, Anderson RH. Atrioventricular septal defects: What's in a name? J Thorac Cardiovase Surg 1982;83:461-9.

2. DeLeon SY, Ilbawi MN, Wilson WR Jr, et al. Surgical options in subaortic stenosis associated with endocardial cushion defects. Ann Thorac Surg 1991;52:1076-82.

3. Reeder GS, Danielson GK, Seward JB, Driscoll DJ, Tajik AJ. Fixed subaortic stenosis in atrioventricular canal defect: a Doppler echocardiographic study. J Am Coll Cardiol 1992; 2:386-94.

4. Manning PB, Mayer JE, Sanders SP, et al. Unique features and prognosis of primum ASD presenting in the first year of life. Circulation 1994;90(Suppl):II30-5.

5. Van Arsdell GS, Williams WG, Boutin C, et al. Subaortic stenosis in the spectrum of atrioventricular septal defects: solutions may be complex and palliative. J Thorac Cardiovase Surg 1995;110:1534-41.

6. Piccoli GP, Ho SY, Wilkinson JL, Macartney FJ, Gerlis LM, Anderson RH. Left-sided obstructive lesions in atrioventricular septal defects: an anatomic study. J Thorac Cardiovasc Surg 1982;83:453-60.

7. Taylor NC, Sommerville J. Fixed subaortic stenosis after repair of ostium primum defects. Br Heart J 1981;45:689-97. 
8. Chang CI, Becker AE. Surgical anatomy of left ventricular outflow tract obstruction in complete atrioventricular septal defect: a concept for operative repair. $\mathbf{J}$ Thorac Cardiovasc Surg 1987;94:897-903.

9. Lappen RS, Muster AJ, Idriss FS, et al. Masked subaortic stenosis in ostium primum atrial septal defect: recognition and treatment. Am J Cardiol 1983;52:336-40.

10. Starr A, Hovaguimian H. Surgical repair of subaortic stenosis in atrioventricular septal defects. J Thorac Cardiovasc Surg 1994;108:373-6.

11. Draulans-Noe HA, Wenink AC. Anterolateral muscle bundle of the left ventricle in atrioventricular septal defect: left ventricular outflow tract and subaortic stenosis. Pediatr Cardiol 1991;12:83-8.

12. Ebels T, Ho SY, Anderson RH, Meijboom EJ, Eijgelaar A.
The surgical anatomy of the left ventricular outflow tract in atrioventricular septal defect. Ann Thorac Surg 1986;41: 483-8.

13. Iwahara M, Ino $\mathrm{T}$, Hosoda $\mathrm{Y}$, et al. Clinical features of aortic arch anomaly with malalignment ventricular septal defect. Ann Thorac Surg 1989;48:693-6.

14. Bove EL, Minich LL, Pridjian AK, et al. The management of severe subaortic stenosis, ventricular septal defect, and aortic arch obstruction in the neonate. J Thorac Cardiovasc Surg 1993;105:289-96.

15. Ebels T, Meijboom EJ, Anderson RH, et al. Anatomic and functional "obstruction" of the outflow tract in atrioventricular septal defects with separate valve orifices ("ostium primum atrial septal defect"): an echocardiographic study. Am J Cardiol 1984;54:843-7.

\section{ON THE MOVE? \\ Send us your new address at least six weeks ahead}

Don't miss a single issue of the journal! To ensure prompt service when you change your address, please photocopy and complete the form below.

Please send your change of address notification at least six weeks before your move to ensure continued service. We regret we cannot guarantee replacement of issues missed due to late notification.

JOURNAL TITLE:

Fill in the title of the journal here.

\section{OLD ADDRESS:}

Affix the address label from a recent issue of the journal here.

\section{NEW ADDRESS:}

Clearly print your new address here.

Name

Address

City/State/ZIP
COPY AND MAIL THIS FORM TO:

Journal Subscription Services

Mosby-Year Book, Inc.

11830 Westline Industrial Dr.

St. Louis, MO 63146-3318
OR FAX TO:

314-432-1158

N/ Mosby
OR PHONE:

1-800-453-4351

Outside the U.S., call

314-453-4351 